\title{
Prescriptive Analysis on Instructional Structure of MOOCs: Toward Attaining Learning Objectives for Diverse Learners
}

\author{
Yuki Ichimura*, Keiko Noda**, Hiroshi Nakano*** and Katsuaki Suzuki****
}

(Received 6 September 2019 and accepted in revised form 14 March 2020)

\begin{abstract}
Instructional design significantly impacts participants' learning experiences and retention in massive open online courses (MOOCs). Although MOOCs have been increasingly adopted on a wide scale, structure of concrete design components for ensuring high learning experience quality have not been elucidated so far. This study conducted detailed examination of five existing MOOCs from multiple countries using revised Bloom's taxonomy and Merrill's component display theory. The cognitive levels determined by the learning contents and assessment activities were analyzed and correlated with instructional sequential analysis. The results provided clear distinctions for good practice, thereby indicating prescriptive design choices to realize learning objectives for diverse learners.
\end{abstract}

Keywords: assessment, Bloom's taxonomy, component display theory, instructional design, MOOCs

\section{Introduction}

Massive open online courses (MOOCs) have been evolving since the launch of the first course in 2008 . MOOCs have contributed to developing new forms of online learning as well as providing experimental opportunities for instructors, as if "MOOCs are testing the limits of technology, instruction, and learning ${ }^{(1)}$ ( $\mathrm{p}$. 253)." Likewise, discussions on the pedagogy of MOOCs and its effectiveness have received considerable attention. Among these, the issue of low completion rates is frequently noted. Recent trends indicate that some researchers have been shifting their position, focusing more on the learning experience than on course completion rates ${ }^{(1,2)}$. However, no consensus has yet been emerged with regard to the quality measurement of MOOCs ${ }^{(3)}$. Responding to this concern in a previous study, we created the 10 Dimensions Model $^{(4)}$ by analyzing and synthesizing certain design elements of MOOCs. The current study focused on the pedagogical dimension in association with learning objectives.

While obtaining participants' learning experiences

* Graduate School of Instructional Systems, Kumamoto University, Japan

** Section Manager, Dalton Tokyo Junior \& High School, Japan

*** Center for Management of Information Technologies, Kumamoto University, Japan

**** Research Center for Instructional Systems, Kumamoto University, Japan and course evaluations are a common means to assess the quality of learning in MOOCs, instructional design (ID) also provides a reliable quality indicator. Margaryan et al. ${ }^{(3)}$ measured the degree to which ID principles were employed in 76 randomly selected MOOCs, finding poor quality ${ }^{(3)}$. Most MOOCs were under supported, with even basic ID components lacking ${ }^{(3)}$. Among ID elements, Jung et al. ${ }^{(5)}$ reported that the instructional structure and learners' interaction with learning contents were particularly important for effective MOOC learning. Despite the potential of ID principles, design of instructional structure and learning transaction for effective pedagogy in MOOCs has not been thoroughly examined. It, therefore, seems crucial to examine what effective ID-supported courses are like and how ID theories can be realized in practices. Specifically, the current situation calls for more prescriptive design choices, particularly in reference to the scalability and diversity inherent in MOOCs.

The purpose of this study is, therefore, to analyze instructional structures, learning contents, and assessment activities of existing MOOCs with ID taxonomies, and extract how MOOCs can be effectively designed for diverse learners' objectives. Responding to the design issues identified in past research, we used Revised Bloom's Taxonomy and Merrill's Component Display Theory (CDT) as the theoretical background in order to obtain implications for overcoming the design difficulties of MOOCs. 


\section{Literature Review}

\subsection{Difficulties of Massive Open Classes}

The concept of MOOCs indicates the inevitable complexity involved in learning design, arising from issues of scalability and diversity ${ }^{(6,7)}$. Past MOOC studies specifically identified issues related to diverse learners' needs. According to Buhl, Andreason and Pushpandum ${ }^{(7)}$, the most challenging design problem was that learners advanced by relying on themselves or on technology, but not on the instructors. They maintain that scaffolding remains essential for self-directed learning ${ }^{(7)}$.

Watson et al. ${ }^{(8)}$ reported issues in determining difficulty levels for massive audiences. Upon receipt of numerous complaints regarding the difficulty levels of quizzes from participants, they needed to alter the policy during the course. Diverse learners' different needs were directly reflected in the perceived depth of learning that caused stress. In reality, it is not feasible to provide individual feedback to support massive groups of learners. Watson et al. ${ }^{(8)}$ suggested new MOOC structures, supporting personal and flexible learning paths for diverse learning objectives and needs. Clear presentation of the objectives and prerequisites to the learners were suggested $^{(8)}$. According to Mangaryan et al. ${ }^{(3)}$, the majority of MOOCs that they examined did not have measurable learning objectives or had no objectives.

Many MOOCs often provide two tracks, including paid certification tracks and free audit tracks in the same course. However, MOOC learners' goals are not just dichotomous. Rather, participants have their own learning objectives $^{(5)}$. Self-directed MOOC learners are "concerned more with achieving their learning goals, and not only with achieving high performance"(5) (p. 385). Diverse learning goals are fundamentally different from the degree-attaining regular courses. Different learning goals from the traditional instructional settings necessitate learning contents and assessment that align with objectives.

\subsection{Revised Bloom's Taxonomy}

Bloom's taxonomy for classifying learning objectives has a wide use among educators. This two-dimensional taxonomy table consists of the Cognitive Process Dimension, representing what students do, and the Knowledge Dimension, which is the domain of knowledge $^{(9)}$. The taxonomy offers potential for responding to the design difficulties in diverse learning goals. To date however, there have been very few studies that have used the taxonomy in MOOC research.

Kauffman and Kauffman ${ }^{(2)}$ reported their MOOC design experience using Bloom's taxonomy and classified the course objectives and the activities in table format. Bali ${ }^{(10)}$ examined four MOOCs with the taxonomy and reported that all courses were similar, while some courses included assignments and discussions that required relatively higher order thinking. Nonetheless, the study reported the researchers' personal experiences and analyzed general course activities. Seeking a more in-depth analysis, the current study analyzed the MOOCs by giving particular attention to the pedagogical approach employed.

\subsection{Instructional Structure and Presentation}

Multiple studies have questioned the quality of MOOCs, often in reference to problems associated with their instructional structure. Ebben and Murphy noted that "most MOOCs are structured in a uni-directional manner"(11) (p. 14). In this regard, MOOCs are often associated with a knowledge transfer model, which merely uses lecture videos and multiple-choice quizzes as major instructional components. Many MOOCs subscribed by the major MOOC providers appear to favor this style of instruction.

Regarding the instructional presentation, Merrill summarized the primary presentation mode in Component Display Theory $(\mathrm{CDT})^{(12)}$. CDT defines instructional presentation in four modalities across two dimensions. The content mode is represented in either Instances (examples) or Generality (principles, rules, theories), while the presentation mode is represented by either Expository (representing knowledge) or Inquisitory (learning activities) (Figure 1). Merrill conceives of instructional presentations as a sequence of interrelationships between these primary forms. The theory attempts to allow learners to make sequential decisions during their learning processes ${ }^{(12)}$. This scope of learners' self-directed control appears to correlate well with MOOC characteristics. In Merrill's theory, each segment should include all presentation forms that are necessary for achieving the objectives. Instructional structure should have clear and easy navigation so that students can easily locate, skip, or review a segment ${ }^{(12)}$. Our review indicates that to date, there is no study analyzing MOOC structure with CDT. 


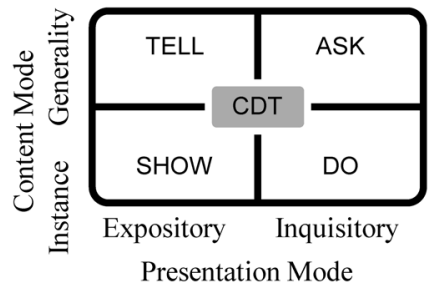

Figure 1. CDT Primary Presentation Form ${ }^{(13)}$.

\section{Research Method}

\subsection{Examined MOOCs}

We observed five MOOCs operating during 2017. Observation methods included describing the details of learning objectives, instructional segments, learning activities, and assessment activities. The first and second authors registered as learners in the selected MOOCs and examined the courses. The courses included (1) Linear Circuit 1: DC Analysis by Georgia Tech University on Coursera (2) Programming for Everybody by University of Michigan on Coursera, (3) Circuit and Electronics 1 (MITx 6.002.1x) by Massachusetts Institute of Technology (MIT) on edX, (4) Denki Kairo (Electric Circuit) delivered by Japan Massive Open Online Education Promotion Council (JMOOC) on the Fisdom platform, and (5) Designing Online Courses with the 7Cs Framework from Bath Spa University on The European Multiple MOOC Aggregator (EMMA). These courses were chosen on the bases of the operating time to examine them, institutions in different countries, and use of multiple platforms.

\subsection{Procedure}

The research procedure was two-fold. First, we examined the intended cognitive processes and knowledge domains in a typical module of each course, using Revised Bloom's Taxonomy ${ }^{(9)}$. Data were collected from each question in the quizzes and from the course information, activities, assignments, and other assessment instructions.

Second, a sequential analysis was conducted to enable comparisons between three of the MOOCs that taught the same subject in the field of electronics: Course 1,3 , and 4 . We listed all the sequences of the courses and the questions of the quizzes first. The smallest learning segments such as lecture videos, quizzes, and lab activities were listed in order and then analyzed using $\mathrm{CDT}^{(12)}$.

The analysis process involved three steps: First, the two reviewers independently examined and classified the segments using Revised Bloom's taxonomy and CDT. Next, agreement rates between the two researchers' analysis results were calculated. Finally, the researchers discussed the data collation with input obtained from the experienced instructional designer, in order to attain objective agreements in relation to the data.

\section{Results}

\subsection{Levels of Learning \& Assessment}

The results indicated that most of the examined MOOCs did not accommodate sufficient levels of activities to fulfill the diverse learners' objectives or their internal course objectives. Two of the courses stimulated the top level cognitive process. Table 1 summarizes the combinations of the levels observed in the courses.

Online quizzes were the most common form of assessment activity, with 4 out of 5 courses utilizing quizzes. Courses 1 and 4 had quizzes only for the learning and assessment activity, while all the questions were on the "procedural" knowledge and "applying" level (C3 in Table 1). In the other courses, quizzes were used on multiple levels. Our in-depth analysis of each question revealed that the form of learning activity could not be associated with a single domain level in the taxonomy table.

Most of the MOOCs under review provided only limited levels of activities, on only one or two levels. All 5 courses had activities categorized in the $\mathrm{C} 3$ domain overlap. This domain appeared most common among the examined courses. Some courses integrated more higher order activities. For example, course 2 integrated "Python Playground" activities where learners practice coding on the platform. Just two of the courses extended the cognitive level up to the "create" stage. For instance, edX's extended online lab function allows course 3 participants the opportunity to practice the knowledge gained from the lecture videos. In this online lab, the learners can create and experiment with circuit diagrams.

Despite using a simple learning management system, notable design features that inspired higher levels of cognitive processes were nevertheless found. Course 5 integrated a variety of learning activities by linking external online applications, such as Google Docs. This course uti- 
Table 1. Summary of Revised Bloom's Taxonomy Analysis.

\begin{tabular}{|c|c|c|c|c|c|c|c|}
\hline \multirow{7}{*}{$\begin{array}{l}\text { Knowledge } \\
\text { Dimension }\end{array}$} & & \multicolumn{6}{|c|}{ The Cognitive Process Dimension } \\
\hline & & \multicolumn{4}{|l|}{ Lower Order } & \multicolumn{2}{|c|}{ Higher Order } \\
\hline & & 1. Remember & 2. Understand & 3. Apply & 4. Analyze & 5. Evaluate & 6. Create \\
\hline & D. Metacognitive & & & & & & \\
\hline & C. Procedural & & & Course $1,2,3,4,5$ & & Course 2, 5 & Course 3,5 \\
\hline & B. Conceptual & & Course 3 & & & Course 5 & Course 5 \\
\hline & A. Factual & & & & & & \\
\hline
\end{tabular}

lizes only discussion boards as the task submission tool on the platform itself. The learners upload their work through the external web services, including social network services, and post links to the discussion boards. Despite the simple structure, it extended two knowledge domains to the higher order levels of "evaluate" and "create".

Agreement rates between the reviewers were mixed for the courses. Three of the courses resulted in ratings of $90 \%$, $97.1 \%$, and $100 \%$. Low agreement rates were achieved for courses 3 and 5 , which were $35 \%$ and $8 \%$, respectively. The learning tasks of these two courses occurred in multiple modes and involved further complexity in determining domains and levels. Course analysis included insights from an experienced instructional designer that enabled the finalization of the objective agreements after discussion and data alignment by both reviewers.

\subsection{Structure of Instructional Sequences}

Our examination suggested that the instructional sequence of each module has a significant impact on the course design as a whole. We analyzed each instructional sequence and the length of time needed, utilizing Merrill's $\mathrm{CDT}^{(12)}$ (Figure 2). Only one course indicated estimated time for learning activities and quizzes. We, therefore, subtracted the sum of video length from the minimum module completion time stated on the course description to estimate the time required for the learning activities.

The ratio of the primary presentation forms was quite distinctive between the courses. Figure 2 comprises the comparison of sequencing analysis using CDT. While course 3 balanced Expository and Inquisitory modes, the two other courses were obviously knowledge exposition oriented. In course 4, "Tell" was 51\%, which accounted for an extremely large portion compared to the other courses. In turn, "Do" constituted only 12.7\%. "Ask" was not included in the three courses.

The arrangement of the presentation forms was clearly different between the three courses. Notable differences were found in the arrangement and the volume of learning activities that were classified as "Do" (Table 2). Course 1 repeated the combinations of lecture videos

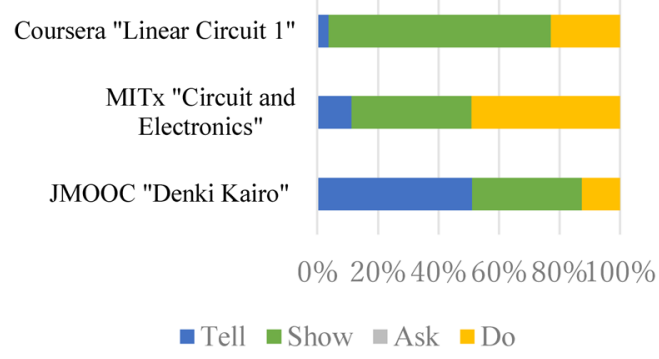

Figure 2. CDT Analysis.

and quizzes. "Do" activities were distributed across all the segments. Although videos were mostly associated with "Tell" and "Show", course 1 utilized a new presentation method, in which "Do" was integrated in the videos. During lecture videos, questions showed up and the learners were encouraged to solve them. Course 3 distributed "Do" activities across the module after presenting the videos. These did not have basic repetition patterns, which gave the impression of complexity to gain a sense of progress. In contrast, course 4 located quizzes at the very last part of the module. In this course, three lecture videos of "Tell" and "Show" formed big chunks in the module. Comparatively, there was a wide gap in the volume of the instructional contents. This was most notably reflected in the expected module learning time, which ranged from a minimum, one-hour commitment, to the longest counterpart, which was six times as long. All courses allowed learners to locate and review the learning segments, depending on their needs.

\section{Discussion}

Among the five courses examined with Revised Bloom's taxonomy, two courses had only a single level of C3 (Table 1). Anderson and Krathwhol ${ }^{(9)}$ suggest a sample instructional unit, in which seven combinations (B2, B4, B5, C3, C5, D1, and D3) of activities and assessment were integrated for attaining one objective (B3). Using this understanding, it would, therefore, be difficult to 
Table 2. CDT Alignment Patterns of the three "Electronic Circuit" MOOCs.

\begin{tabular}{|l|c|c|c|}
\hline Courses & Topics in a Module & Module completion Time & Basic CDT Alignment Pattern \\
\hline Course 1 & 6 & $5.5 \mathrm{H}$ & Do (\%) \\
\hline Course 3 & 2 & $5-7 \mathrm{H}$ & VTR(Tell/Show/Do) $\rightarrow$ Quizzes $($ Do) $/$ each topic \\
\hline Course 4 & 1 & $1 \mathrm{H}$ & No pattern, VTR(Tell/Show), Quizzes (Do), Lab (Do) \\
\hline
\end{tabular}

attain an objective by only a single level. In addition, two courses did not have any learning objectives stated. Clear objectives are necessary to avoid potential mismatches between instructional goals and learners' needs.

Carefully analyzing objectives and designing multiple activities from the different cells in the taxonomy table are crucial, especially in the design of MOOCs. These are necessary not only for attaining the course objectives set out by the instructors, but are also crucial for MOOC learners, since they assist in the choices and adjustments along the path for achieving their diverse objectives. The frustrations the learners reported in previous studies are understandable because many MOOCs repeat the same levels of activities or provide only a few combinations of domains and levels. These are insufficient for accommodating large audiences and achieving their goals.

The design of activity levels and the basic module structures were also compared. The two heavily Expository-oriented courses had a lesser amount of "Do" activities in single levels of C3. Courses that fairly balanced Expository and Inquisitory segments displayed a variety of levels, such as B3, C3, and C6. Some courses linked external online tools and facilitated high cognitive levels. Platforms and technical resources did not necessarily restrain the extension of activity levels, rather, it appeared that the instructional design was inadequate. In the current study there was no meta-cognitive knowledge activity observed. This could be due to the chosen subject areas; however, in the MOOC context, meta-cognitive dimensions should be included in order for the students to reflect on and analyze (D3) their own process of study ${ }^{(9)}$.

In addition, the identified MOOC activities from this study are listed in Table 3. Related activity verbs and possible choices flowing from these were added. Having examined the descriptive analysis on the existing MOOCs (Table $1 \& 2$, and Figure 2), more varieties of enriched MOOC learning activities were mapped with the taxonomy, considering diverse needs (Table 3). Upon them, as a prescribed example, the following design adjustments are suggested in the case of course 4 . The module improvement is considered under the given conditions of the resources in course 4 .

Firstly, divide the big chunks of the 4 sequences into smaller units, thus reforming the general module
Table 3. Instructional Activities in MOOCs by the Taxonomy.

\begin{tabular}{|l|l|l|}
\hline & Levels & Instructional Activities in MOOC \\
\hline H & Create & $\begin{array}{l}\text { Lab, Objective creation, Create and share works, Plan } \\
\text { a research, Hypothesizing alternative ways, Planning, } \\
\text { Producing, Building }\end{array}$ \\
\cline { 2 - 3 } & Evaluate & $\begin{array}{l}\text { Lab, Forum, Peer-Grading others' assignment, } \\
\text { Respond to classmates, } \\
\text { Judging, Monitoring, Testing }\end{array}$ \\
\cline { 2 - 3 } & Analyze & $\begin{array}{l}\text { Lab, Graphic Organization } \\
\text { Distinguishing, Determining, }\end{array}$ \\
\cline { 2 - 3 } & Apply & $\begin{array}{l}\text { Quizzes, Coding, Wiki, Web searching and reporting, } \\
\text { Using procedures, Executing, Implementing }\end{array}$ \\
\cline { 2 - 3 } & Understand & $\begin{array}{l}\text { Quizzes, Forum, Paraphrasing, Listing examples, } \\
\text { Categorizing, Summarizing, Comparing, Cause-Effect } \\
\text { listing }\end{array}$ \\
\cline { 2 - 3 } L & Remember & Recall Quizzes, Recognizing \\
\hline
\end{tabular}

(Anderson and Krathwohl ${ }^{(9)}$ )

structure. The three lecture videos are currently 12 to 22 minutes long, of which over 50\% are "Tell". These should be divided according to their topics and reduced to a maximum of 10 minutes each. Not only through lecture videos, general rules can be presented with other complementary materials, such as PDF files or web resources. In this way, learners can refer to just the necessary information whenever it is needed. In direct instruction, offer more examples, such as problem sets. In course 4 , the fixed power point slides provide the only visual cues. However, to show problem solving processes, some other MOOCs simply captured the instructor's handwriting on paper. Another suggestion is to immediately follow each short video clip with an aligned "Do" sequence. By spreading such learning activities across the module, the module structure will be transformed from a "Tell" dominant to a "Do" oriented one, where learners will have more opportunities to actively execute learning at their own pace.

Furthermore, the "Do" sequence can be improved using Bloom's taxonomy analysis. The course objective of course 4 was C5. In order to achieve this, wider levels of learning activities beyond the current $\mathrm{C} 3$ are necessary. Practice quizzes can involve higher levels of cognitive processes. For example, ask students to evaluate and choose a circuit that works as an effective solution in a given condition. This process involves distinguishing (C4) and judging (C5) the right circuit from other multiple choices. In addition, have learners record their problem-solving process on a document file during their quiz activities, and share it on discussion boards. 
Let them evaluate others' work (C5), and then monitor and reflect on their own learning process $(\mathrm{D} 3,5)$.

These prescriptive suggestions should appear on the course objectives as the primary foundation ${ }^{(8)}$. Activity and assessment design processes involve questions of what students learn, how to deliver instruction, how to assess students' learning, and how objectives, instruction, and assessment are consistently attained ${ }^{(9)}$. Multiple combinations of instructional activities will allow learners to adjust their learning paths ${ }^{(5)}$. The taxonomy table provides effective indicators not only for instructors, but should benefit all MOOC learners. By indicating Bloom's taxonomy levels on instructional activities, learners can choose their activities in a more effective manner ${ }^{(12)}$.

\section{Conclusion}

In designing MOOCs, the volume of participants and diversity of learners are complex issues. Responding to the difficulties addressed by the previous researchers, this study suggests factors contributing toward learners attaining their own goals. MOOC learners are unique in having their own learning goals that might exceed the limitations of the primary course objectives provided ${ }^{(8)}$. Learner control and flexibility are some of the key solutions supported by the previous study and ID theories. This study analyzed five current MOOCs utilizing ID taxonomies and suggested ways to make them more effective in supporting learners' selfdirected learning, while simultaneously assisting in the attainment of course providers' internal course objectives. With MOOCs, it is not feasible to adjust course contents to meet the diverse needs of participants. A personal recommendation system using big data would be a possible solution for personalization. Sufficient learning activities, aligned with the objectives, instruction, and assessment, are the primary prescriptions gained from an ID analysis of the currently reviewed MOOCs.

\section{References}

(1) Bonk, C. J., Reeves, T. C., Lee, M. M. et al.: "The Emergence and Design of Massive Open Online Courses", in Trend and Issues in Instructional Design and Technology, eds. Reiser, R. A. and Dempsey, J. V., Pearson, Boston, MA (2018).

(2) Kauffman,Y. and Kauffman, D.: "MOOCs Design and Development: Using Active Learning Pedagogy and
Instructional Design Model in MITx Courses on the edX Platform", Proc. of EdMedia: World Conference on Educational Media and Technology, AACE: Quebec, pp. 22-27 (2015).

(3) Margaryan, A., Bianco, M. and Littlejohn, A.: "Instructional Quality of Massive Open Online Courses (MOOCs)", Computers \& Education, Vol. 80, pp. 77-83 (2015).

(4) Ichimura, Y. and Suzuki, K.: "Dimensions of MOOCs for Quality Design: Analysis and Synthesis of the Literature", International J. for Educational Media and Technology, Vol. 11, No. 1, pp. 42-49 (2017).

(5) Jung, E., Kim, D., Yoon, M. et al.: "The Influence of Instructional Design on Learner Control, Sense of Achievement, and Perceived Effectiveness in a Supersize MOOC Course", Computers \& Education, Vol. 128, pp. 377-388 (2019)

(6) Dennen, V. P. and Bong, J.: "Behind the Scenes of an Independent MOOC: Instructional Design Problems and Solutions", International J. for Educational Media and Technology, Vol. 9, No. 1, pp. 25-31 (2015).

(7) Buhl, M., Andreasen, L. B. and Pushpanadham, K.: "Upscaling the Number of Learners, Fragmenting the Role of Teachers: How Do Massive Open Online Courses (MOOCs) form New Conditions for Learning Design?", International Review of Education, Vol. 64, No. 3, pp. 179-195 (2018).

(8) Watson, S. L., Loizzo, J., Watson, W. R. et al.: "Instructional Design, Facilitation, and Perceived Learning Outcomes: An Exploratory Case Study of a Human Trafficking MOOC for Attitudinal Change", Educational Technology Research and Development, Vol. 64, No. 6, pp. 1273-1300 (2016).

(9) Anderson, L. W. and Krathwohl, D. R.: “A Taxonomy for Learning, Teaching, and Assessing: A Revision of Bloom's Taxonomy of Educational Objectives", New York: Longman (2001).

(10) Bali, M. B.: "MOOC Pedagogy: Gleaning Good Practice from Existing MOOCs", J. of Online Learning \& Teaching, Vol. 10, No. 1, pp. 44-56 (2014).

(11) Ebben, M. and Murphy, J. S.: "Unpacking MOOC Scholarly Discourse: A Review of Nascent MOOC Scholarship", Learning Media and Technology, Vol. 39, No. 3, pp. 328-345 (2014).

(12) Merrill, M. D. and Twitchell, D.: Instructional Design Theory, Educational Technology Publications, New Jersey (1994).

(13) Suzuki, K.: Learner Control and Structured Method for Supporting Self-Regulated Learning. Human Information Science and e-Learning, Hoso-Daigaku Kyoiku Shinkokai, Tokyo (2006). (in Japanese) 